\title{
Calmodulin and $\mathrm{Ca}^{2+} /$ Calmodulin-Binding Proteins are Involved in Tetrahymena thermophila Phagocytosis
}

\author{
Kohsuke Gonda, Mie Komatsu, and Osamu Numata* \\ Institute of Biological Sciences, University of Tsukuba, Tennoudai 1-1-1, Tsukuba, Ibaraki 305-8572, Japan
}

\begin{abstract}
The ciliated protist, Tetrahymena thermophila, possesses one oral apparatus for phagocytosis, one of the most important cell functions, in the anterior cell cortex. The apparatus comprises four membrane structures which consist of ciliated and unciliated basal bodies, a cytostome where food is collected by oral ciliary motility, and a cytopharynx where food vacuoles are formed. The food vacuole is thought to be transported into the cytoplasm by a deep fiber which connects with the oral apparatus. Although a large number of studies have been done on the structure of the oral apparatus, the molecular mechanisms of phagocytosis in Tetrahymena thermophila are not well understood. In this study, using indirect immunofluorescence, we demonstrated that the deep fiber consisted of actin, $\mathrm{CaM}$, and $\mathrm{Ca}^{2+} / \mathrm{CaM}$-binding proteins, $\mathrm{p85}$ and $\mathrm{EF}-1 \alpha$, which are closely involved in cytokinesis. Moreover, we showed that CaM, p85, and EF-1 $\alpha$ are colocalized in the cytostome and the cytopharynx of the oral apparatus. Next, we examined whether $\mathrm{Ca}^{2+} / \mathrm{CaM}$ signal regulates Tetrahymena thermophila phagocytosis, using $\mathrm{Ca}^{2+} / \mathrm{CaM}$ inhibitors chlorpromazine, trifluoperazine, $\mathrm{N}$-(6-aminohexyl)-1naphthalenesulfonamide, and N-(6-aminohexyl)-5-chloro-1-naphthalenesulfonamide HCl. In Tetrahymena, it is known that $\mathrm{Ca}^{2+} / \mathrm{CaM}$ signal is closely involved in ciliary motility and cytokinesis. The results showed that one of the inhibitors, $\mathrm{N}$-(6-aminohexyl)-5-chloro-1-naphthalenesulfonamide $\mathrm{HCl}$, inhibited the food vacuole formation rather than the ciliary motility, while the other three inhibitors effectively prevented the ciliary motility. Considering the colocalization of $\mathrm{CaM}, \mathrm{p85}$, and $\mathrm{EF}-1 \alpha$ to the cytopharynx, these results suggest that the $\mathrm{Ca}^{2+} / \mathrm{CaM}$ signal plays a pivotal role in Tetrahymena thermophila food vacuole formation.
\end{abstract}

Key words: $\quad$ actin/calmodulin/EF-1 $\alpha /$ phagocytosis/p85/Tetrahymena

The ciliated protist, Tetrahymena, has one oral apparatus for phagocytosis, in the anterior cell cortex. The oral apparatus is a funnel-like structure, and mainly comprises three membranelles, an undulating membrane, and a ribbed wall which exists in between the three membranelles and the undulating membrane (Fig. 1A, B) (Frankel, 1999). The membrane

\footnotetext{
* To whom correspondence should be addressed: Institue of Biological Sciences, University of Tsukuba, Tennoudai 1-1-1, Tsukuba, Ibaraki 3058572, Japan.

Tel and Fax: +81-298-53-6648

E-mail: numata@sakura.cc.tsukuba.ac.jp

Abbreviations: CaM, calmodulin; CaR1, affinity-purified rabbit antiTetrahymena calmodulin antibody 1; CPZ, chlorpromazine hydrochloride; DMSO, dimethyl sulfoxide; EF- $1 \alpha$, elongation factor $1 \alpha$; EFR1, affinity-purified rabbit anti-Tetrahymena EF-1 $\alpha$ antibody 1; F-actin, filamentous actin; NP-40, Nonidet P-40; p85GP1, guinea pig anti-p85 antiserum 1; SDS-PAGE, sodium dodecylsulfate-polyacrylamide gel electrophoresis; TAGP5, guinea pig anti-Tetrahymena thermophila actin antiserum 5; TFP, trifluoperazine hydrochloride; W5, N-(6-aminohexyl)-1naphthalenesulfonamide hydrochloride; W7, N-(6-aminohexyl)-5-chloro1-naphthalenesulfonamide $\mathrm{HCl}$.
}

structures of the oral apparatus consist of ciliated and unciliated basal bodies (Frankel, 1999). In addition, underlying the ribbed wall is a crescent-shaped structure (Fig. 1A, B) (Williams and Bakowska, 1982). In the innermost part of the funnel-like structure, a cytostome, a cytopharynx, and a cytostomal lip, which is a projection separating the cytostome from the cytopharynx, can be seen adjacent to the ribbed wall (Fig. 1B) (Elliott and Kennedy, 1973). It is thought that in Tetrahymena, food is gathered into the cytostome by ciliary motility of the oral membrane structures, and then a food vacuole is formed in the cytopharynx (Elliott and Kennedy, 1973; Nilsson, 1979). Although the system for transporting the food vacuole into the cytoplasm is not well understood, a deep fiber which courses inward from the cytostome may be involved.

The architecture of the oral apparatus is classified into a microtubular structure and nonmicrotubular components. The microtubular structure includes connectives among the three membranelles and the undulating membrane (Kiers- 
(A)

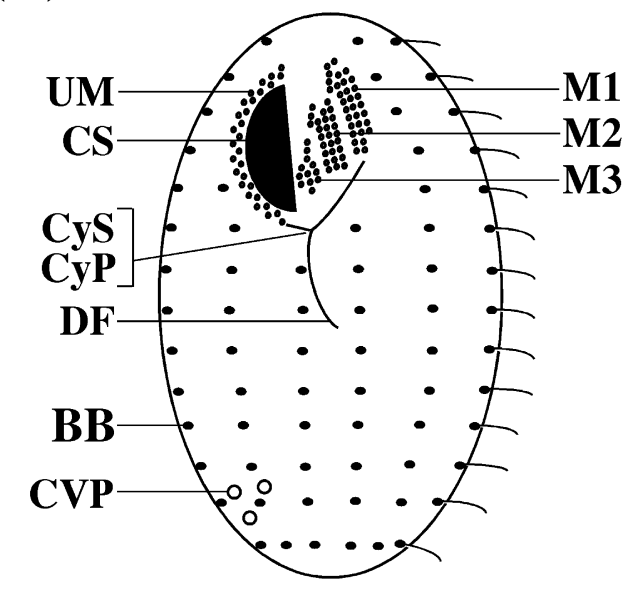

(B)

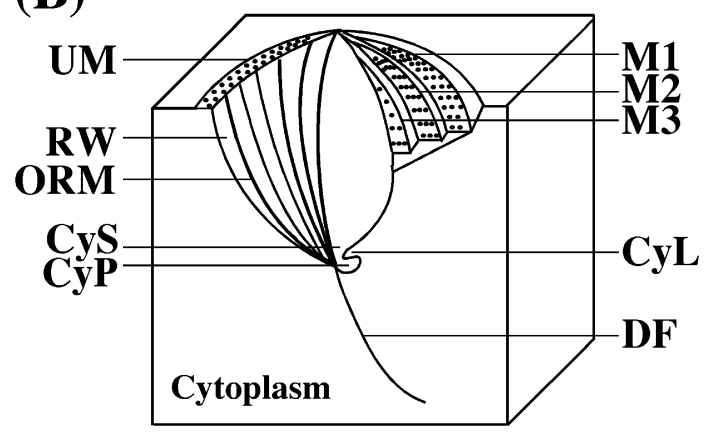

Fig. 1. Schematic diagrams of the cortical organization of $T$. thermophila. (A) Cortical structure. (B) Three-dimensional structure of the oral apparatus. M1-3, three membranelles. UM, undulating membrane. These membrane structures are mainly composed of ciliated and unciliated basal bodies. CS, crescent-shaped structure. CyS and CyP show cytostome and cytopharynx, respectively, and indicate the region where these structures exist. DF, deep fiber. The deep fiber extends from the cell cortex into the cytoplasm. BB, basal body which possesses cilia. CVP, contractile vacuole pores. RW, ribbed wall. ORM, oral-rib microtubules. CyL, cytostomal lip.

nowska and Golinska, 1996; Williams and Luft, 1968). In addition, there are the oral-rib microtubules in the ribbed wall and the microtubules in the deep fiber (Kiersnowska and Golinska, 1996; Williams and Luft, 1968). Williams and Bakowska demonstrated that the deep fiber microtubulules are inward continuations of the oral-rib microtubules (Williams and Bakowska, 1982). Previous studies showed that some proteins existed in the oral apparatus as nonmicrotubular components. In Tetrahymena pyriformis ( $T$. pyriformis), actin was localized in the three membranelles and the undulating membrane (Hirono et al., 1987) and coexisted with the actin-modulating protein, fimbrin, in the deep fiber (Watanabe et al., 1998; Watanabe et al., 2000). By immunofluorescence staining of T. pyriformis, CaM was observed in the three membranelles, the undulating membrane, and the crescent-shaped structure (Suzuki et al., 1982). Honts and Williams isolated filamentforming proteins, tetrins, from $T$. pyriformis cortical cytoskeleton and showed that they were localized in the oral apparatus (Honts and Williams, 1990). In addition, Numata et al. found that $T$. pyriformis citrate synthase formed 14$\mathrm{nm}$ filaments and that immunofluorescent staining for this protein was seen in the $\tau$-shaped region which corresponds to the root part of the deep fiber (Numata et al., 1983; Numata, 1996). In Tetrahymena thermophila (T. thermophila), actin was detected ultrastructurally in the basal body cages of isolated oral apparatus, by the immunogold technique (Hoey and Gavin, 1992). Fimbrin was also localized in $T$. thermophila deep fiber (Watanabe et al., 1998). These findings provide useful information on the structure of the oral apparatus. However, the molecular mechanisms of Tetrahymena phagocytosis have not been well understood.

Phagocytosis also has been studied well in other eukaryotic cells. In Dictyostelium discoideum (D. discoideum), it was shown that profilin acted as a negative regulator of phagocytosis, since profilin-null cells were more efficient in phagocytosis than wild type cells (Temesvari et al., 2000). In addition, a number of key phagosomal pathway regulatory proteins have been identified in $D$. discoideum, including actin (Jenne et al., 1998), $\alpha$-actinin (Furukawa and Fechheimer, 1994), coronin (Maniak et al., 1995), and low-molecular-weight GTPase Rab7 (Buczynski et al., 1997), RacC (Seastone et al., 1998), and Rap1 (Seastone et al., 1999). In the mouse macrophage cell line J774.A1, the colocalization of Arp2/3 complex and actin was observed in the phagosome during Fc $\gamma$ receptor and complement receptor-mediated phagocytosis (May et al., 2000), and the recruitment of Arp2/3 and actin to phagosome was controlled by the small GTPase Rho, Cdc42, and Rac1 (May et al., 2000). Moreover, phagocytosis of macrophage cell line J774.16 cells was inhibited by $\mathrm{Ca}^{2+} / \mathrm{CaM}$ inhibitor TFP and W7 (Horwitz et al., 1981). From these results, it is thought that the actin cytoskeleton, small GTPase, and $\mathrm{Ca}^{2+} / \mathrm{CaM}$ signal play an important role in eukaryotic phagocytosis.

We have used Tetrahymena for studying cytokinesis. In the cytokinesis of animal cells, first, a division plane is determined at the cellular equator and then an actomyosinbased contractile ring appears at the division plane. The contractile ring constricts, generates a division furrow, and divides the cell (Satterwhite and Pollard, 1992; Schroder, 1968). We previously reported that actin (Gonda et al., 1999a) and actin-modulated protein, EF-1 $\alpha$ (Numata et al., 2000), were localized in a furrow in T. thermophila. EF-1 $\alpha$ binds to F-actin and induces F-actin bundles in vitro (Kurasawa et al., 1996). Therefore, EF-1 $\alpha$ may bundle Factin in the contractile ring. $\mathrm{EF}-1 \alpha$ also binds to $\mathrm{CaM}$ in a $\mathrm{Ca}^{2+}$-dependent manner, and $\mathrm{Ca}^{2+} / \mathrm{CaM}$ inhibits the formation of F-actin bundles by EF-1 $\alpha$ (Kurasawa et al., 1996). T. 
thermophila p85 is localized to the presumptive division plane before the formation of the contractile ring (Gonda et al., 1999a; Numata et al., 1995; Ohba et al., 1986), and the contractile ring is thought to be formed where p85 is localized in the division plane (Gonda et al., 1999a). In addition, Ohba et al. reported immunofluorescent staining of p85 in the membrane structures and the crescent-shaped structure of the T. thermophila oral apparatus (Ohba et al., 1986). Recently, we found that $\mathrm{p} 85$ interacted directly with CaM in a $\mathrm{Ca}^{2+}$-dependent manner, and that both proteins colocalized in the division furrow during cytokinesis (Gonda et al., 1999a; Gonda et al., 1999b). Moreover, we showed that $\mathrm{Ca}^{2+} / \mathrm{CaM}$ inhibitor W7 inhibited the direct interaction between $\mathrm{p} 85$ and $\mathrm{Ca}^{2+} / \mathrm{CaM}$, the localization of $\mathrm{p} 85$ and $\mathrm{CaM}$ to the division plane, and some events downstream of $\mathrm{p} 85$, such as the formation of a contractile ring and division furrow (Gonda et al., 1999a). Therefore, the direct interaction of $\mathrm{p} 85$ and $\mathrm{Ca}^{2+} / \mathrm{CaM}$ may determine the division plane and play a crucial role in the formation of the contractile ring.

In this study, to clarify the mechanisms of $T$. thermophila phagocytosis, we further examined the localization of actin, $\mathrm{CaM}$, and $\mathrm{Ca}^{2+} / \mathrm{CaM}$-binding proteins, p85 and $\mathrm{EF}-1 \alpha$, to the oral apparatus in interphase cells, using various immunofluorescence procedures. The results showed that actin is localized in the deep fiber, and that CaM, p85, and EF-1 $\alpha$ are colocalized in the crescent-shaped structure, the cytostome, the cytopharynx, and the deep fiber in $T$. thermophila. Moreover, we report that $\mathrm{Ca}^{2+} / \mathrm{CaM}$ inhibitor W7 inhibits the food vacuole formation in $T$. thermophila. We also discuss the mechanisms of phagocytosis regulated by $\mathrm{CaM}$ and $\mathrm{Ca}^{2+} / \mathrm{CaM}$-binding proteins.

\section{Materials and Methods}

\section{Cell culture}

Cultivation of Tetrahymena thermophila (B24964WT) was performed as described previously (Watanabe et al., 1994).

\section{Antibodies \\ A guinea pig anti-p85 antiserum p85GP1 (Ohba et al., 1986), a guinea pig anti-T. thermophila actin antiserum TAGP5 (Gonda et al., 1999a), an affinity-purified rabbit anti-Tetrahymena CaM anti- body CaR1 (Gonda et al., 1999a), and an affinity-purified rabbit anti-Tetrahymena EF-1 $\alpha$ antibody EFR1 (Numata et al., 2000) were prepared as described previously.}

\section{Immunofluorescence}

Immunofluorescence microscopy was performed using two different techniques. First, to immunostain actin, the cells were washed with $\mathrm{S}$ buffer $\left(7.5 \mathrm{mM} \mathrm{Na}_{2} \mathrm{HPO}_{4}, 2.5 \mathrm{mM} \mathrm{NaH}_{2} \mathrm{PO}_{4}\right.$, and $100 \mathrm{mM} \mathrm{NaCl}, \mathrm{pH}$ 7.2), incubated in $\mathrm{S}$ buffer for $5 \mathrm{~min}$ at room temperature, air-dried on slides, and fixed with methanol for 30 $\min$ at $-80^{\circ} \mathrm{C}$. After a wash with $\mathrm{S}$ buffer, the cells were incubated at room temperature with $5 \%$ nonfat-dried milk in S buffer for 30 min, and then with TAGP5 (diluted 1:100 in S buffer) for 2 hours. After a wash with $\mathrm{S}$ buffer, they were incubated with rhodamineconjugated anti-guinea pig IgG antibodies (KPL, Gaithersburg, MD, USA; diluted 1:100 in S buffer) for 2 hours at room temperature. After a final wash with $\mathrm{S}$ buffer, the cells were observed with a Karl Zeiss Axio fluorescence microscope and photographed with Tri-X Pan 400 film (Kodak, Rochester, NY, USA). Second, to double-immunostain $\mathrm{p} 85$ and $\mathrm{CaM}$ or $\mathrm{p} 85$ and $\mathrm{EF}-1 \alpha$, an immunofluorescent technique using a cell model was applied (Goodenough, 1983). The cells were treated with $0.25 \%$ NP-40, air-dried on slides, and then fixed with $3 \%$ paraformaldehyde in phosphatebuffered saline (PBS) for $30 \mathrm{~min}$ at $4{ }^{\circ} \mathrm{C}$. After a wash with PBS, the cells were incubated sequentially with $0.1 \mathrm{M}$ glycine in PBS for $30 \mathrm{~min}$ at $4^{\circ} \mathrm{C}$, with $5 \%$ nonfat-dried milk in PBS for $30 \mathrm{~min}$ at room temperature, with p85GP1 (diluted 1:50 in PBS) and CaR1 (diluted 1:4 in PBS) or p85GP1 (diluted 1:50 in PBS) and EFR1 (diluted 1:4 in PBS) for 2 hours at room temperature, and with rhodamine-conjugated anti-guinea pig IgG antibodies (KPL; diluted 1:100 in PBS) for p85 and FITC-conjugated anti-rabbit IgG antibodies (KPL; diluted 1:500 in PBS) for CaM and EF-1 $\alpha$, for 2 hours at room temperature. The cells were washed with PBS after each incubation.

\section{Inhibitory experiments on $\mathrm{Ca}^{2+} / \mathrm{CaM}$ inhibitors $\mathrm{CPZ}$, TFP, W5, and $W 7$}

To observe the effect of CPZ (Wako, Osaka, Osaka, Japan), TFP (SIGMA, St. Louis, MO, USA), W5 (SIGMA), and W7 (ICN, Aurora, $\mathrm{OH}, \mathrm{USA}$ ) on the phagocytosis, these inhibitors dissolved in $0.2 \%$ DMSO were added to log-phase cultures, and the cultures incubated at $26^{\circ} \mathrm{C}$. After incubation for $15 \mathrm{~min}, 2 \%$ red India ink (Kaimei, Urawa, Saitama, Japan) was added to the culture and the ratio of the cells forming carbon-containing food vacuoles and the number of food vacuoles in a cell were then determined.

\section{Results}

\section{Localization of Actin, CaM, p85, and EF-1 $\alpha$ in T. thermophila Oral Apparatus}

In $T$. pyriformis, previous studies revealed that actin and $\mathrm{CaM}$ were localized to the membranelles and the undulating membrane of the oral apparatus and the deep fiber (Fig. 1A, B) (Hirono et al., 1987; Suzuki et al., 1982). CaM was also localized in the crescent-shaped structure of the oral apparatus (Fig. 1A) (Suzuki et al., 1982). In T. thermophila, we showed that the $\mathrm{Ca}^{2+} / \mathrm{CaM}$-binding and actin-crosslinking protein EF-1 $\alpha$ was localized to the crescent-shaped structure of the apparatus (Numata et al., 2000), and that the localization of $\mathrm{p} 85$ was observed in the membranelles, the undulating membrane, and the crescent-shaped structure (Ohba et al., 1986). In addition, Hoey and Gavin reported that actin was localized in the basal body cages of the isolated oral apparatus (Hoey and Gavin, 1992). However, the 
functions of actin, CaM, p85, and EF-1 $\alpha$ in phagocytosis still remain unknown. To understand the molecular mechanisms of phagocytosis, we reinvestigated the localization of these proteins in the $T$. thermophila oral apparatus, using various immunofluorescence procedures.

In T. thermophila, it was not known whether actin exists in the deep fiber and the division furrow. We recently prepared a guinea pig anti- $T$. thermophila actin antiserum TAGP5 and succeeded in immunostaining actin filaments of the contractile ring in T. thermophila with TAGP5, using cells permeated and fixed with methanol (Fig. 2A) (Gonda et al., 1999a). We next examined the localization of actin in $T$. thermophila interphase cells, utilizing TAGP5. T. thermophila actin was detected in the deep fiber in interphase (Figs. 1A, B, 2B) and, as in yeast, actin patches formed during the cell cycle (Fig. 2A, B). Since the deep fiber degenerates during cytokinesis, the localization of actin in the deep fiber was not observed during cytokinesis (Fig. 2A). These observations for actin could not be made by indirect immunofluorescence microscopy using a guinea pig preimmune serum (data not shown).

Next, to investigate the localization of $\mathrm{CaM}$ and $\mathrm{Ca}^{2+}$ CaM-binding proteins, $\mathrm{p} 85$ and EF-1 $\alpha$ in T. thermophila oral apparatus, double immunostaining for p85 and either $\mathrm{CaM}$ or EF-1 $\alpha$ was carried out, using cells fixed with $3 \%$ paraformaldehyde after permeation with $0.25 \%$ NP- 40 . In interphase cells, p85 and CaM (Fig. 3A, B) or p85 and EF$1 \alpha$ (Fig. 3C, D) colocalized in the deep fiber. These results show that actin, CaM, p85, and EF-1 $\alpha$ colocalize in the
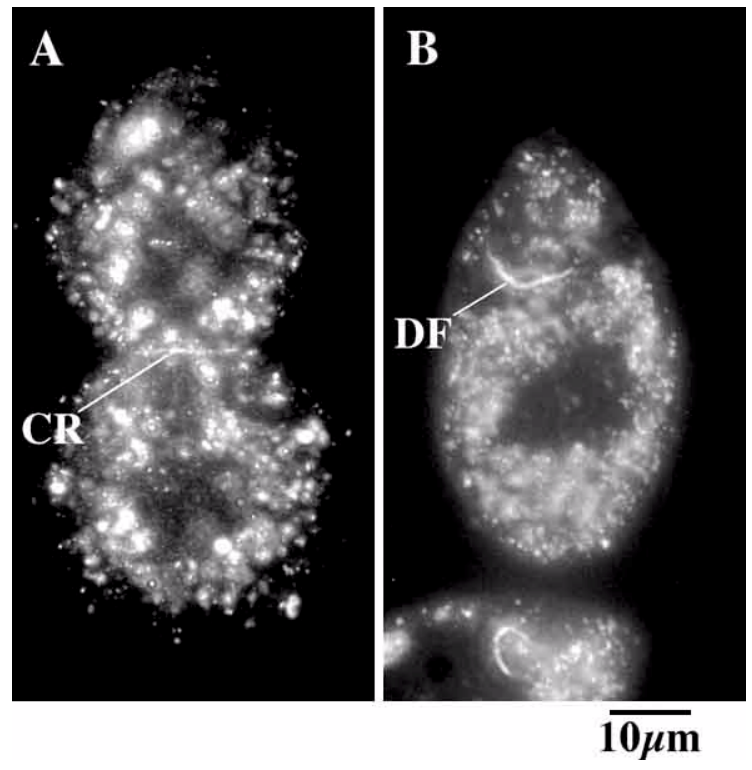

Fig. 2. Immunofluorescent localization of actin during the cell cycle. Immunofluorescent images for actin with TAGP5 in the middle phase of cytokinesis (A) and interphase (B) are represented. CR and DF show the contractile ring and the deep fiber, respectively. In all photographs, the anterior regions of the cells are aligned on the upper side.
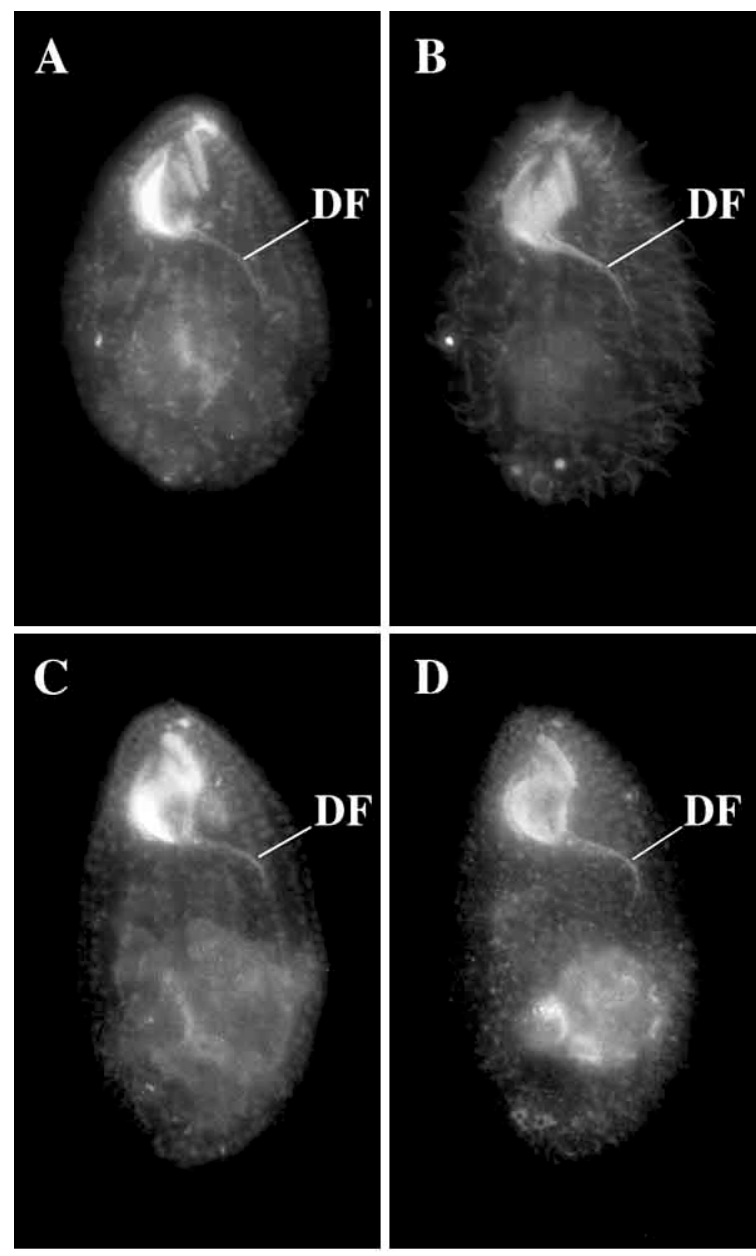

$\overline{10 \mu \mathrm{m}}$

Fig. 3. Immunofluorescent localization of $\mathrm{p} 85, \mathrm{CaM}$, and EF-1 $\alpha$ in interphase cells. Double-immunofluorescent images for p85 (A) and CaM (B), and those for p85 (C) and EF-1 $\alpha$ (D) are shown. DF, deep fiber. The anterior regions of the cells are aligned on the upper side.

deep fiber of $T$. thermophila. In addition, immunofluorescence for $\mathrm{p} 85, \mathrm{CaM}$, and $\mathrm{EF}-1 \alpha$ was seen in the membranelles, the undulating membrane, and the crescentshaped structure of the oral apparatus (Figs. 1A, B, 3A-D). The localization of CaM was also observed in cilia (Fig. 3B) (this data will be reported in another paper), as in T. pyriformis (Suzuki et al., 1982). Immunofluorescence of EF$1 \alpha$ was also seen in the macronucleus (Fig. 3D). More noteworthy is that $\mathrm{CaM}$ and $\mathrm{Ca}^{2+} / \mathrm{CaM}$-binding proteins, p85 and EF-1 $\alpha$, colocalized in the cytostome and the cytopharynx of the oral apparatus where the deep fiber connects (Figs. 1A, B, 3A-D). In T. thermophila phagocytosis, it is thought that food is collected into the cytostome by the oral ciliary motility and then a food vacuole is formed in the cytopharynx. Therefore, CaM, p85, and EF-1 $\alpha$ may cooperate in regulating the formation of the food vacuole. These 
localizations were not detected by indirect immunofluorescence using a rabbit and a guinea pig control sera (data not shown).

\section{T. thermophila phagocytosis is inhibited by $\mathrm{Ca}^{2+} / \mathrm{CaM}$ inhibitor $W 7$}

Since $\mathrm{CaM}$ and two $\mathrm{Ca}^{2+} / \mathrm{CaM}$-binding proteins, p85 and EF-1 $\alpha$, colocalized in the cytostome and the cytopharynx of the oral apparatus which is closely involved in $T$. thermophila phagocytosis, we next investigated whether $\mathrm{Ca}^{2+} / \mathrm{CaM}$ signaling actually regulates $T$. thermophila phagocytosis, using CPZ, TFP, W5, and W7. CPZ and TFP, phenothiazine-derivatives, and W5 and W7, naphtalenesulfonamide-derivatives, are known well as $\mathrm{Ca}^{2+} / \mathrm{CaM}$ inhibitors. These drugs bind to $\mathrm{CaM}$ in a $\mathrm{Ca}^{2+}$-dependent manner and inhibit the binding of $\mathrm{Ca}^{2+} / \mathrm{CaM}$ to its binding protein (Craven et al., 1996; Hidaka et al., 1981; Levin and Weiss, 1976; Osawa et al., 1998; Palacios et al., 1993). To observe the effect of these inhibitors on the phagocytosis, the inhibitors dissolved in DMSO were added to log-phase cell cultures and the cells were incubated at $26^{\circ} \mathrm{C}$. After incubation for $15 \mathrm{~min}$, India ink was added to the cell culture and then the effect of inhibitors on phagocytosis was investigated. The ratio of cells forming carbon-containing food vacuoles decreased depending on the dosage of inhibitor (Fig. 4). Although the treatment with $50 \mu \mathrm{M} \mathrm{CPZ}, 30 \mu \mathrm{M}$ TFP, $800 \mu \mathrm{M} \mathrm{W} 5$, and $150 \mu \mathrm{M}$ W7 did inhibit the ciliary motility, some activity remained (data not shown). Moreover, while, in the cells treated with CPZ, TFP, and W5, the ratio of cells forming carbon-containing vacuoles increased gradually, in the cells treated with 150 $\mu \mathrm{M} \mathrm{W7}$, it did not increase and was steady at approximately $66 \%(125 \mu \mathrm{M})$ and 44\% (150 $\mu \mathrm{M})$ (Fig. 4). From these results, we conclude that $\mathrm{W} 7$ is more effective for observing $\mathrm{Ca}^{2+} / \mathrm{CaM}$ signaling in $T$. thermophila phagocytosis, a mat- ter to be considered further in the Discussion.

Next, in the cells treated with $50 \mu \mathrm{M} \mathrm{CPZ,} 30 \mu \mathrm{M}$ TFP, $800 \mu \mathrm{M} \mathrm{W} 5,150 \mu \mathrm{M} \mathrm{W7}$, and DMSO alone, we examined the number of food vacuoles in each cell. The results showed that the number of food vacuoles was smaller in the cells treated with inhibitors than in the cells treated with DMSO alone (Fig. 5, 6).

In the cells treated with $50 \mu \mathrm{M} \mathrm{CPZ}, 30 \mu \mathrm{M}$ TFP, 800 $\mu \mathrm{M} \mathrm{W} 5$, and $150 \mu \mathrm{M} \mathrm{W7}$, carbon-containing food vacuoles were not accumulated in the region connecting the deep fiber with the cytopharynx (Fig. 6). Thus, it is thought that these inhibitors do not prevent the transport of the food vacuole from the cytopharynx to cytoplasm. Considering the colocalization of CaM, p85, and EF-1 $\alpha$ in the cytopharynx of the oral apparatus, these results suggest that the $\mathrm{Ca}^{2+} /$ $\mathrm{CaM}$ signal is involved in the food vacuole formation. In addition, when the cells treated with $150 \mu \mathrm{M}$ W7 were transferred to fresh medium at $40 \mathrm{~min}$ after the treatment with W7, they performed phagocytosis normally. Thus, the effect of $\mathrm{W} 7$ on phagocytosis is reversible.

Finally, to examine the effect of $150 \mu \mathrm{M} \mathrm{W7}$ on the localization of $\mathrm{CaM}$ and $\mathrm{Ca}^{2+} / \mathrm{CaM}$-binding proteins, p85 and EF-1 $\alpha$, to the oral apparatus, we observed the localization of CaM, p85, and EF-1 $\alpha$ in the cells in which W7 completely inhibited the formation of carbon-containing food vacuoles. The results showed that W7 did not disturb the localization of CaM, p85, and EF-1 $\alpha$ in the oral apparatus and the deep fiber (Fig. 7). In addition, we previously showed that $100 \mu \mathrm{M}$ W7 inhibited the binding of $\mathrm{Ca}^{2+} / \mathrm{CaM}$ and $\mathrm{p} 85$ and thereby prevented initiation of cytokinesis. Therefore, these results suggest that the treatment with $\mathrm{W} 7$ does not affect the structure of the oral apparatus, though it prevents the binding of $\mathrm{Ca}^{2+} / \mathrm{CaM}$ and its target protein in the structure. In these inhibitory experiments on $\mathrm{Ca}^{2+} / \mathrm{CaM}$ inhibitors, the treatment with DMSO alone had no effect on phagocytosis.
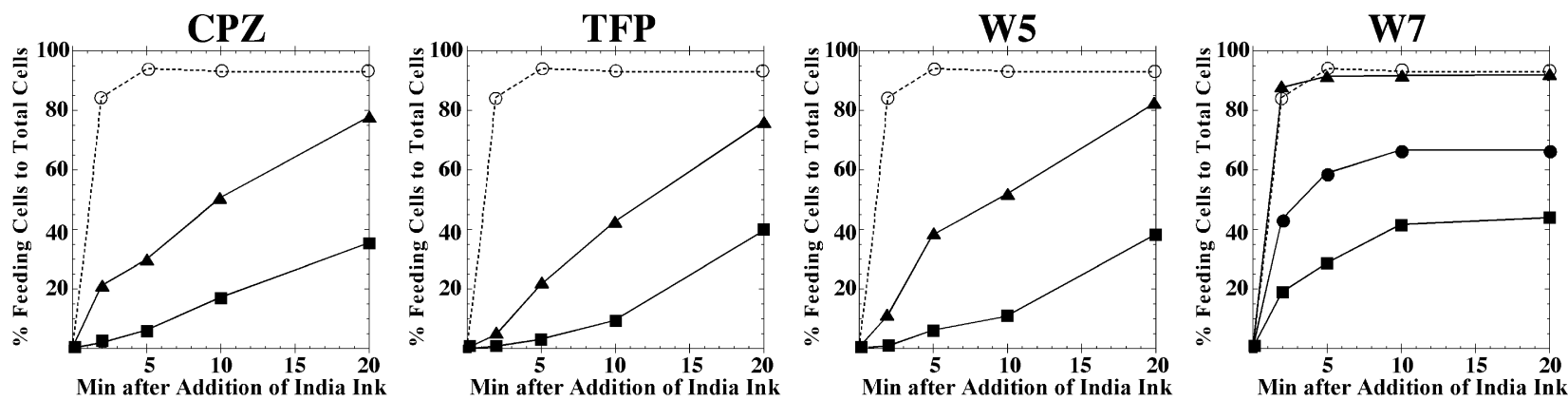

Fig. 4. Effects of $\mathrm{Ca}^{2+} / \mathrm{CaM}$ inhibitors on the ratio of the cells forming carbon-containing food vacuoles. Log-phase cell cultures were incubated with various concentrations of $\mathrm{Ca}^{2+} / \mathrm{CaM}$ inhibitor at $26^{\circ} \mathrm{C}$. After incubation for $15 \mathrm{~min}$, India ink was added to the culture and the cells were then fixed with $1.9 \%$ formalin at the indicated time. CPZ: $\mathbf{\Delta}, 30 \mu \mathrm{M} ; \boldsymbol{\square}, 50 \mu \mathrm{M}$. TFP: $\boldsymbol{\Delta}, 20 \mu \mathrm{M} ; \boldsymbol{\square}, 30 \mu \mathrm{M}$. W5: $\mathbf{\Delta}, 600 \mu \mathrm{M} ; \boldsymbol{\square}, 800 \mu \mathrm{M}$. W7: $\mathbf{\Delta}, 100 \mu \mathrm{M} ; \mathbf{O}, 125 \mu \mathrm{M} ; \boldsymbol{\square}$, $150 \mu \mathrm{M}$. In all line graphs, open circles $(\bigcirc)$ with dashed lines show the cells treated with DMSO alone. The abscissa represents time (min) after the addition of India ink and the ordinate shows the population of cells ingesting carbon. At the indicated time at various inhibitor concentrations, 200-300 cells were counted. The results are representative of three independent experiments. 
$50 \mu \mathrm{M}$ CPZ

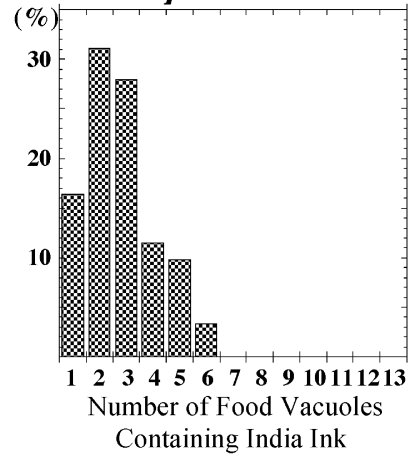

DMSO

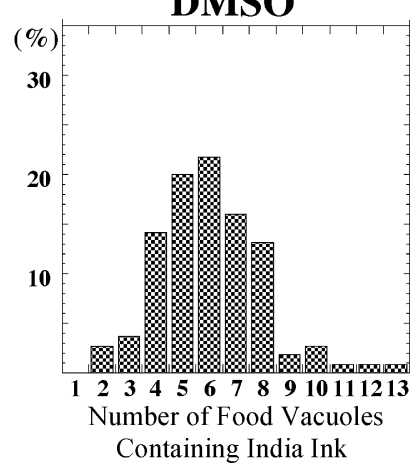

30 $\mu \mathrm{M}$ TFP

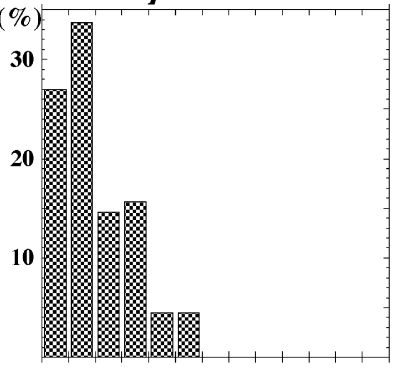

123456788910111213

Containing India Ink
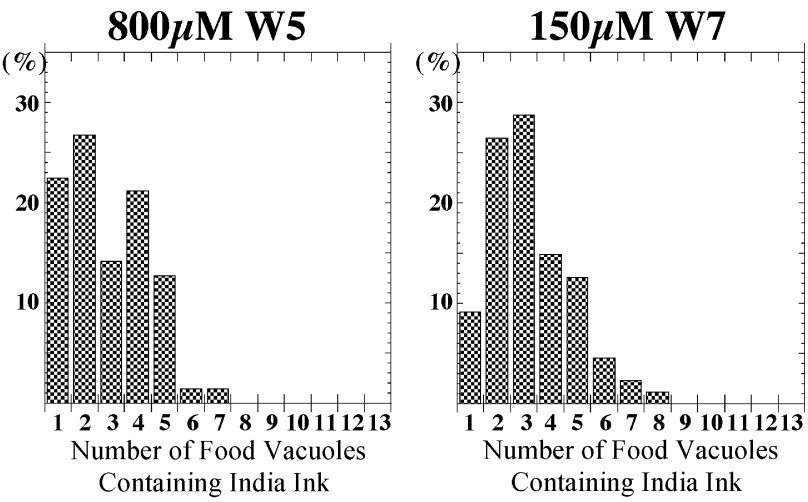

Fig. 5. Effects of $\mathrm{Ca}^{2+} / \mathrm{CaM}$ inhibitors on the number of carbon-containing food vacuoles in each cell. Cell cultures were incubated with $50 \mu \mathrm{M} \mathrm{CPZ}, 30$ $\mu \mathrm{M}$ TFP, $800 \mu \mathrm{M} \mathrm{W5}, 150 \mu \mathrm{M} \mathrm{W7}$, or DMSO alone at $26^{\circ} \mathrm{C}$. After incubation for $15 \mathrm{~min}$, India ink was added to the culture, as in Fig. 4 . In each histogram, at $20 \mathrm{~min}$ after the addition of India ink, the number of carbon-containing food vacuoles in the cells was counted. In CPZ: av.=2.8, $\mathrm{n}=124$. In TFP: av. $=2.5, n=93$. In W5: av. $=2.8, n=77$. In W7: av. $=3.3, n=94$. In DMSO: $a v .=6.8, n=106$. The abscissa shows the number of carbon-containing food vacuoles in the cells and the ordinate the population of cells. The results are representative of three independent experiments.

\section{Discussion}

In T. thermophila phagocytosis, first, food is collected into the cytostome of the oral apparatus by ciliary motility (Fig. 1A, B). Next, to ingest the food, vacuoles are formed in the cytopharynx of the oral apparatus (Fig. 1A, B), and then transported into the cytoplasm by an unknown mechanism. The deep fiber which connects with the oral apparatus may be involved in the transport (Fig. 1A, B).

In this study, to clarify the molecular mechanisms of phagocytosis, we investigated the localization of $\mathrm{CaM}$ and $\mathrm{Ca}^{2+} / \mathrm{CaM}$-binding proteins, $\mathrm{p} 85$ and $\mathrm{EF}-1 \alpha$, in the $T$. thermophila oral apparatus. The results showed that $\mathrm{CaM}$, p85, and EF-1 $\alpha$ colocalized in the cytostome and the cytopharynx of the oral apparatus (Fig. 3A-D). Therefore, it is thought that the $\mathrm{Ca}^{2+} / \mathrm{CaM}$ signal is closely involved in the formation of food vacuoles in T. thermophila. To investigate whether the $\mathrm{Ca}^{2+} / \mathrm{CaM}$ signal regulates the food vacuole formation, we examined the effect of $\mathrm{Ca}^{2+} / \mathrm{CaM}$ inhibitors CPZ, TFP, W5, and $\mathrm{W} 7$ on $T$. thermophila phagocytosis using India ink. The results showed that the ratio of the cells forming carbon-containing food vacuoles and the number of food vacuoles in each cell decreased de- pending on the dosage of inhibitors (Figs. 4-6). It is known that the $\mathrm{Ca}^{2+} / \mathrm{CaM}$ signal is involved in the ciliary motility (Kink et al., 1990; Suzuki et al., 1982), and that the motility is important for collecting the food into the oral apparatus. Therefore, although it is possible that inhibition of the ciliary motility by inhibitors prevents the food vacuole formation, we suppose that $\mathrm{W} 7$ affects the formation rather than the motility, while CPZ, TFP, and W5 affect the motility rather than the formation, for the following reason. Although the treatments with $50 \mu \mathrm{M} \mathrm{CPZ}, 30 \mu \mathrm{M}$ TFP, 800 $\mu \mathrm{M} \mathrm{W} 5$, and $150 \mu \mathrm{M} \mathrm{W7}$ partially inhibited the activity of ciliary motility, some activity remained. In the cells treated with CPZ, TFP, and W5, the ratio of cells forming carboncontaining food vacuoles increased gradually (Fig. 4). These results suggest that, since the formation of food vacuoles is little affected by CPZ, TFP, and W5, the cells treated with these inhibitors can gradually form food vacuoles using the remaining activity of ciliary motility. In other words, it is thought that, in the cells treated with CPZ, TFP, and W5, the inhibition of food vacuole formation is caused only by the inhibition of the ciliary motility. Likewise, Suzuki et al. previously showed that in T. pyriformis cells treated with TFP, the ratio of cells forming carbon-containing vacuoles 
increased gradually (Suzuki et al., 1982), as in this study. In contrast, in the cells treated with $150 \mu \mathrm{M} \mathrm{W7}$, the ratio did not increase and was steady at approximately 44\% (Fig. 4). This result suggests that, since the food vacuole formation is inhibited by $\mathrm{W} 7$, the ratio in the cells treated with $\mathrm{W} 7$ did not increase and was steady in spite of the activity of ciliary motility. In summary, it is supposed that W7 prevents the formation of food vacuoles more effectively than ciliary motility in phagocytosis. Therefore, we proposed that $\mathrm{W} 7$ is more suitable for observation of the $\mathrm{Ca}^{2+} / \mathrm{CaM}$ signal in Tetrahymena phagocytosis than other $\mathrm{Ca}^{2+} / \mathrm{CaM}$ inhibitors. The effectiveness of a $\mathrm{Ca}^{2+} / \mathrm{CaM}$ inhibitor is thought to be related to its ability to permeate the cell membrane and oral apparatus. Moreover, we think that W7 does not affect the transport of the food vacuoles. If W7 does inhibit the transport, the untransported vacuoles ought to be accumulated in the connecting region between the deep fiber and the cytopharynx. However, no such accumulation was observed in the inhibitory experiments with W7 (Fig. 6), indicating that W7 inhibits the formation but does not affect the transport of the food vacuoles. These results suggest that the $\mathrm{Ca}^{2+} / \mathrm{CaM}$ signal regulates the formation of food vacuoles, and that $\mathrm{p} 85$ and $\mathrm{EF}-1 \alpha$ are candidates for the target protein of the $\mathrm{Ca}^{2+} / \mathrm{CaM}$ signal in $T$. thermophila phagocytosis.

Actin, $\mathrm{CaM}$ and two $\mathrm{Ca}^{2+} / \mathrm{CaM}$-binding proteins, $\mathrm{p} 85$ and EF-1 $\alpha$, colocalized in the deep fiber (Figs. 2B, 3A-D). In $T$. thermophila cytokinesis, it is thought that p85 and $\mathrm{Ca}^{2+}$ / $\mathrm{CaM}$ cooperatively regulate the assembly of actin filaments in the division plane (Gonda et al., 1999a), and that EF-1 $\alpha$ may bundle the actin filaments in the contractile ring, the bundling activity being regulated by $\mathrm{Ca}^{2+} / \mathrm{CaM}$ (Kurasawa et al., 1996; Numata et al., 2000). Thus, p85 and EF-1 $\alpha$ may be involved in the formation of the deep fiber under regulation by $\mathrm{Ca}^{2+} / \mathrm{CaM}$. Since $\mathrm{Ca}^{2+} / \mathrm{CaM}$ inhibits the F-actin bundling activity of EF-1 $\alpha$, actin filaments in the deep fiber may not be bundled. In addition, since the $\mathrm{Ca}^{2+} / \mathrm{CaM}$ inhibitor W7 did not affect the transport of the food vacuole (Fig. 6), it is thought that the $\mathrm{Ca}^{2+} / \mathrm{CaM}$ in the deep fiber is not involved in the transport.

In our previous study, since $100 \mu \mathrm{M}$ W7 prevented the binding of p85 and $\mathrm{Ca}^{2+} / \mathrm{CaM}$, we treated the cells with 100 $\mu \mathrm{M} \mathrm{W7}$ before the formation of the contractile ring. The result showed that W7 prevented the appearance of $\mathrm{p} 85$ in the presumptive division plane (Gonda et al., 1999a). However, in this study, we treated the cells with $150 \mu \mathrm{M}$ W7 after the formation of the oral apparatus and the deep fiber. At this concentration, W7 did not affect the localization of CaM, $\mathrm{p} 85$, and EF-1 $\alpha$ in the oral apparatus and the deep fiber (Fig. 7). Therefore, it is supposed that, while W7 affects the interaction among $\mathrm{CaM}$, p85, and $\mathrm{EF}-1 \alpha$ in the oral apparatus and the deep fiber, treatment with W7 does not disturb the localization of these proteins in either structure. CaM, $\mathrm{p} 85$, and EF- $1 \alpha$ are probably being incorporated into a stable structure of the oral apparatus after the formation of the apparatus. In this inhibitory experiment, we treated $T$. thermophila cells with $150 \mu \mathrm{M}$ W7. In $\mathrm{CHO}^{-\mathrm{K}_{1}}$ cells, 100 $\mu \mathrm{M}$ W7 completely inhibited the cell proliferation (Hidaka et al., 1981). Since Tetrahymena possesses three membrane structures, a cell membrane, an outer alveolar membrane, and an inner alveolar membrane (Frankel, 1999), it is thought that the sensitivity to W7 in Tetrahymena is lower than that in culture cells. Therefore, we believe that the W7 concentration used in this experiment is not abnormal. In addition, the applied concentration of naphthalenesulfonamid-derivatives W5 and W7 was higher than that of phenothiozine-derivatives CPZ and TFP. Thus, it is thought that cell permeation by naphtalenesulfonamid-
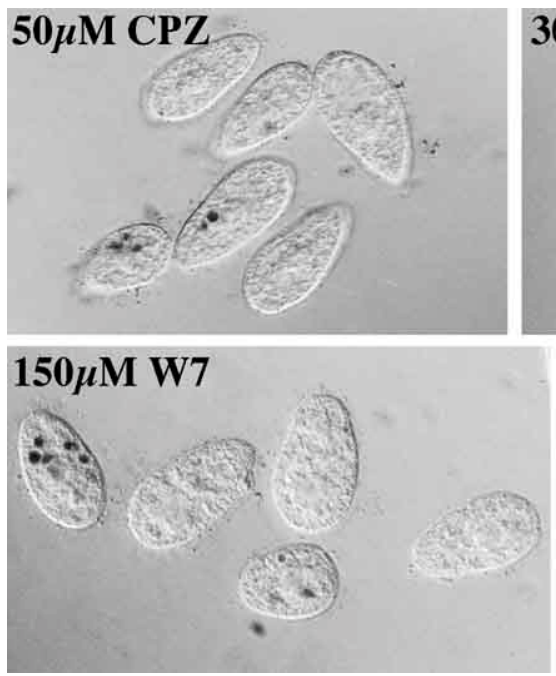
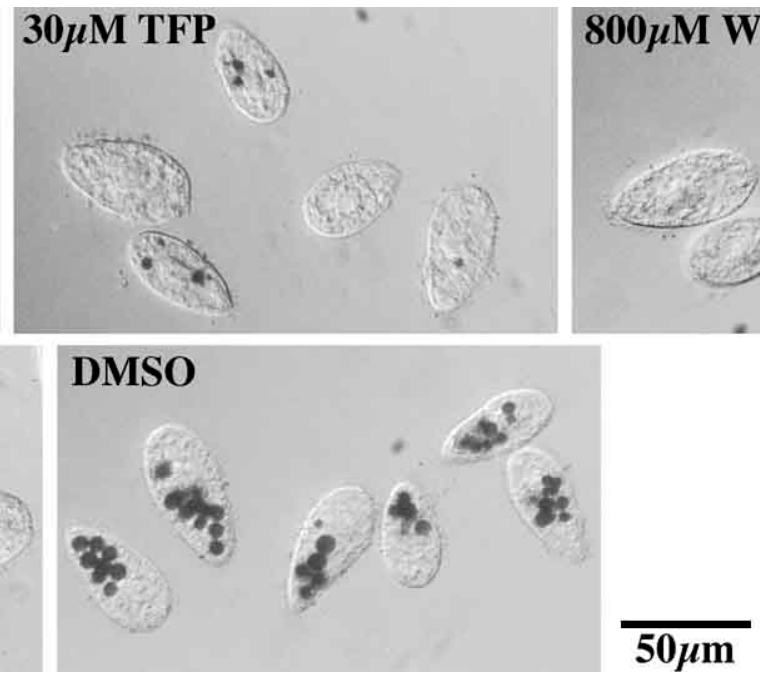

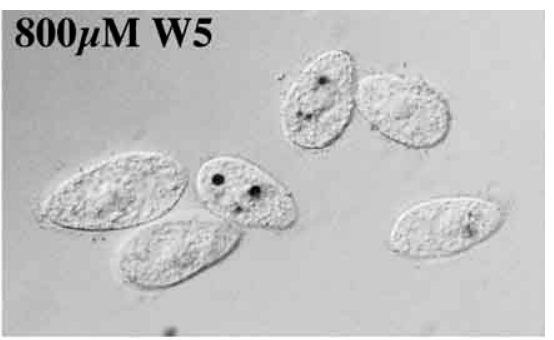

$50 \mu \mathrm{m}$

Fig. 6. Nomarski differential interference-images of the cells treated with $50 \mu \mathrm{M} \mathrm{CPZ,} 30 \mu \mathrm{M}$ TFP, $800 \mu \mathrm{M}$ W5, $150 \mu \mathrm{M}$ W7, and DMSO alone. These images show the cells at 20 min after the addition of India ink. 

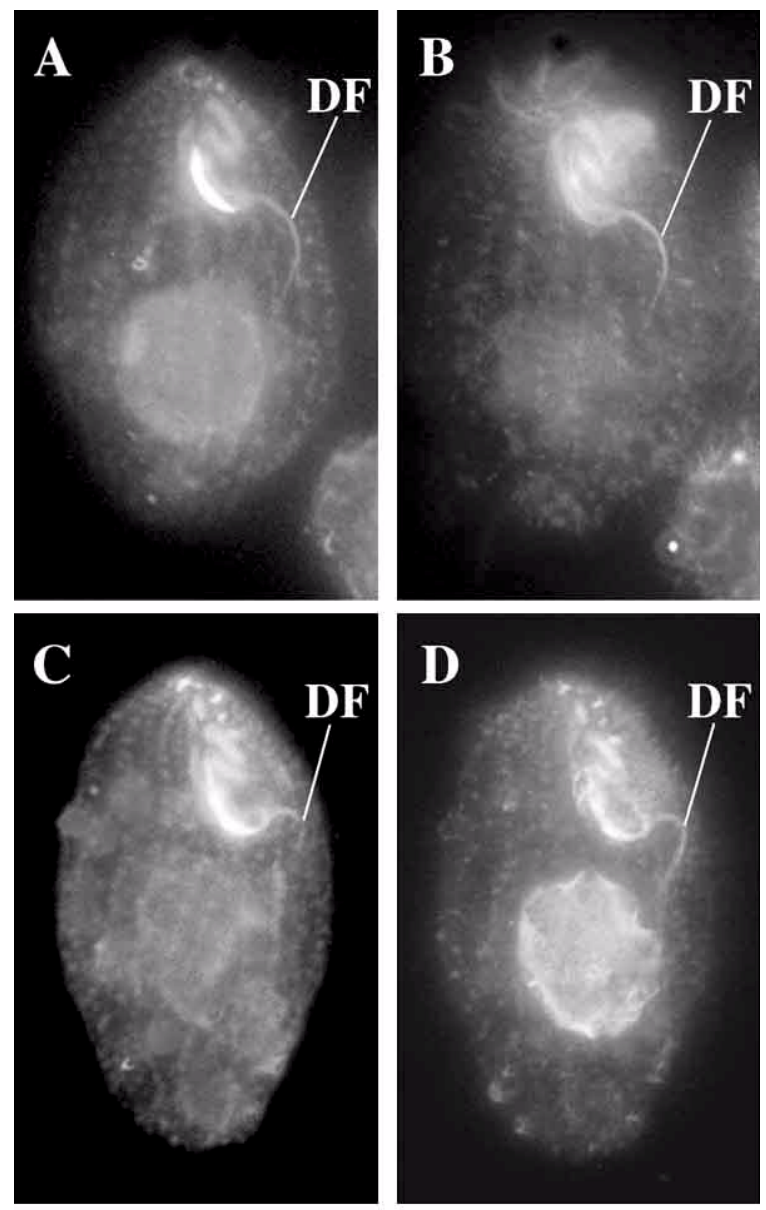

$\overline{10 \mu \mathrm{m}}$

Fig. 7. Immunofluorescent localization of $\mathrm{p} 85, \mathrm{CaM}$, and $\mathrm{EF}-1 \alpha$ in the cells treated with $150 \mu \mathrm{M} \mathrm{W7}$. A log-phase cell culture was incubated with $150 \mu \mathrm{M} \mathrm{W} 7$, and, after incubation for $15 \mathrm{~min}$, India ink was then added to the culture, as in Figs. 4-6. Immunofluorescence was carried out using cells in which W7 completely inhibited the formation of carbon-containing food vacuoles at $20 \mathrm{~min}$ after the addition of India ink. Double-immunofluorescent images for p85 (A) and CaM (B), and those for p85 (C) and EF$1 \alpha$ (D) are shown. DF, deep fiber. The anterior regions of the cells are aligned on the upper side.

derivatives is weaker than that by phenothiozine-derivatives in T. thermophila.

The $\mathrm{Ca}^{2+} / \mathrm{CaM}$ signal is also involved in the phagocytosis of other eukaryotic cells. The phagocytosis of Kupffer cells (Watanabe et al., 1988) and macrophage line J774.16 (Horwitz et al., 1981) cells was prevented by $\mathrm{Ca}^{2+} / \mathrm{CaM}$ inhibitors TFP and $\mathrm{W} 7$, suggesting that $\mathrm{Ca}^{2+} / \mathrm{CaM}$ signal regulates the phagocytosis of these cells. In Dictyostelium, the $\mathrm{Ca}^{2+-}$ binding and actin-crosslinking protein, $\alpha$-actinin, is localized in the phagocytic cup and is thought to be involved in the phagocytosis (Furukawa and Fechheimer, 1994). These results indicate that $\mathrm{Ca}^{2+} / \mathrm{CaM}$ and $\mathrm{Ca}^{2+}$-binding protein are generally crucial to phagocytosis in eukaryotic cells.
Recently, Lee et al. demonstrated that the T. thermophila cytoplasmic dynein heavy chain (Dyh1) regulates phagocytic activity, using gene knockout cells of Dyh1 (Lee et al., 1999). Dynein is a molecular motor that transduces the chemical energy of ATP hydrolysis into mechanical motion along microtubules. In the knockout cells, although the formation of food vacuoles was inhibited, no accumulation of untransported food vacuoles was observed in the connective region between the deep fiber and the cytopharynx. Therefore, Dyh1 may function in the formation of food vacuoles in T. thermophila cells, as well as in $\mathrm{Ca}^{2+} / \mathrm{CaM}$ signaling. Lee et al. did not discuss the molecular mechanisms of phagocytosis in detail (Lee et al., 1999), and the relation between Dyh1 and CaM in the vacuole formation is unknown. It is important to elucidate the relation among Dhy $1, \mathrm{CaM}$, and $\mathrm{Ca}^{2+} / \mathrm{CaM}$-binding proteins in the formation of food vacuoles in T. thermophila.

Acknowledgments. This work was supported by a Research Fellowship to K. G. from the Japan Society for the Promotion of Science for Young Scientists, a Grant-in-Aid for Scientific Research to O. N. from the Ministry of Education, Sciences, Sports and Culture of Japan (06275101, 10213201), and a grant to O. N. from the Yamada Science Foundation.

\section{References}

Buczynski, G., Bush, J., Zhang, L., Rodriguez-Paris, J., and Cardelli, J. 1997. Evidence for a recycling role for Rab7 in regulating a late step in endocytosis and in retention of lysosomal enzymes in Dictyostelium discoideum. Mol. Biol. Cell, 8: 1343-1360

Craven, C.J., Whitehead, B., Jones, S.K., Thulin, E., Blackburn, G.M., and Waltho, J.P. 1996. Complexes formed between calmodulin and the antagonists J-8 and TFP in solution. Biochemistry, 35: 10287-10299.

Elliott, A.M. and Kennedy, J.R. 1973. Morphology of Tetrahymena. In Biology of Tetrahymena (A.M. Elliott ed.) Dowden, Hutchinson \& Ross, Stroudsburg, PA, pp.57-87.

Frankel, J. 1999. Cell Biology of Tetrahymena thermophila. In Methods in Cell Biology (D.J Asai and J.D. Forney eds.). Academic Press, New York, Vol. 62, pp.28-125.

Furukawa, R. and Fechheimer, M. 1994. Differential localization of alphaactinin and the $30 \mathrm{kDa}$ actin-bundling protein in the cleavage furrow, phagocytic cup, and contractile vacuole of Dictyostelium discoideum. Cell Motil. Cytoskeleton, 29: 46-56.

Gonda, K., Katoh, M., Hanyu, K., Watanabe, Y., and Numata, O. 1999a. $\mathrm{Ca}^{2+} /$ Calmodulin and $\mathrm{p} 85$ cooperatively regulate an initiation of cytokinesis in Tetrahymena. J. Cell Sci., 112: 3619-3626.

Gonda, K., Nishibori, K., Ohba, H., Watanabe, A., and Numata, O. 1999 b. Molecular cloning of the gene for p85 that regulates the initiation of cytokinesis in Tetrahymena. Biochem. Biophys. Res. Commun., 264: $112-118$.

Goodenough, U.W. 1983. Motile detergent-extracted cells of Tetrahymena and Chlamydomonas. J. Cell Biol., 96: 1610-1621.

Hidaka, H., Sasaki, Y., Endo, T., Ohno, S., Fujii, Y., and Nagata, T. 1981. N-(6-Aminohexyl)-5-chloro-1-naphthalenesulfonamide, a calmodulin antagonist, inhibits cell proliferation. Proc. Natl. Acad. Sci. USA, 78: 4354-4357.

Hirono, M., Nakamura, M., Tsunemoto, M., Yasuda, T., Ohba, H., Numata, O., and Watanabe, Y. 1987. Tetrahymena actin: localization and possible biological role of actin in Tetrahymena cells. J. Biochem., 102: $537-545$. 
Hoey, J.G. and Gavin, R.H. 1992. Localization of actin in the Tetrahymena basal-body cage complex. J. Cell. Sci., 103: 629-641.

Honts, J.E. and Williams, N.E. 1990. Tetrins: polypeptides that form bundled filaments in Tetrahymena. J. Cell Sci., 96: 293-302.

Horwitz, S.B., Chia, G.H., Harracksingh, C., Orlow, S., Pifko-Hirst, S., Schnech, J., Sorbara, L., Speaker, M., Wilk, E.W., and Rosen, O.N. 1981. Trifluoperazine inhibits phagocytosis in macrophagelike cultured cell line. J. Cell Biol., 91: 798-802.

Jenne, N., Rauchenberger, R., Hacker, U., Kast, T., and Maniak, M. 1998. Targeted gene disruption reveals a role for vacuolin $\mathrm{B}$ in the late endocytic pathway and exocytosis. J. Cell Sci., 111: 61-70.

Kiersnowska, M. and Golinska, K. 1996. Pattern of phosphorylated structures in the morphostatic ciliate Tetrahymena thermophila: MPM-2 immunogold labeling. Acta Protozool., 35: 297-308.

Kink, J.A., Maley, M.E., Preston, R.R., Ling, K.Y., Wallan-Friedman, M.A., Saimi, Y., and Kung, C. 1990. Mutations in paramecium calmodulin indicate functional differences between the $\mathrm{C}$-terminal and $\mathrm{N}$-terminal lobes in vivo. Cell, 62: 165-174.

Kurasawa, Y., Hanyu, K., Watanabe, Y., and Numata, O. 1996. F-actin bundling activity of Tetrahymena elongation factor $1 \alpha$ is regulated by $\mathrm{Ca}^{2+} /$ calmodulin. J. Biochem., 199: 791-798.

Lee, S., Wisniewski, J.C., Dentler, W.L., and Asai, D.J. 1999. Gene knockouts reveal separate functions for two cytoplasmic dyneins in Tetrahymena thermophila. Mol. Biol. Cell, 10: 771-784.

Levin, R.M. and Weiss, B. 1976. Mechanism by which psychotropic drugs inhibit adenosine cyclic 3',5'-monophosphate phosphodiesterase of brain. Mol Pharmacol., 12: 581-589.

Maniak, M., Rauchenberger, R., Albrecht, R., Murphy, J., and Gerisch, G. 1995. Coronin involved in phagocytosis: dynamics of particle-induced relocalization visualized by a green fluorescent protein Tag. Cell, $\mathbf{8 3}$ : 915-924.

May, R.C., Caron, E., Hall, A., and Machesky, L.M. 2000. Involvement of the Arp $2 / 3$ complex in phagocytosis mediated by FcgammaR or CR3. Nat. Cell Biol., 2: 246-248.

Nilsson, J.R. 1979. Phagotrophy in Tetrahymena. In Biochemistry and Physiology of Protozoa (M. Levandowsky and S.H. Huter, eds.). 2nd ed. Academic Press, New York, Vol. 2, pp. 339-379.

Numata, O., Hirono, M., and Watanabe, Y. 1983. Involvement of Tetrahymena intermediate filament protein, a $49 \mathrm{~K}$ protein, in the oral morphogenesis. Exp. Cell Res., 148: 207-220.

Numata, O., Suzuki, H., Ohba, H., and Watanabe, Y. 1995. The mutant gene product of Tetrahymena cell-division-arrest mutant cdaAl is localized in the accessory structure of specialized basal body close to the division furrow. Zool. Sci., 12: 133-135.

Numata, O. 1996. Multifunctional proteins in Tetrahymena: $14 \mathrm{~nm}$ filament protein/citratesynthase and translation elongation factor-1 alpha. Int. Rev. Cytol., 164: 1-35

Numata, O., Kurasawa, Y., Gonda, K., and Watanabe, Y. 2000. Tetrahymena elongation factor-1 $\alpha$ is localized with calmodulin in the division furrow. J. Biochem., 127: 51-56.

Ohba, H., Ohmori, I., Numata, O., and Watanabe, Y. 1986. Purification and immunofluorescence localization of the mutant gene product of a
Tetrahymena cdaAl mutant affecting cell division. J. Biochem., 100: 797-808.

Osawa, M., Swindells, M.B., Tanikawa, J., Tanaka, T., Mase, T., Furuya, T., and Ikura, M. 1998. Solution structure of calmodulin-W-7 complex: the basis of diversity in molecular recognition. J. Mol. Biol., 276: 165176.

Palacios, M., Padron, J., Glaria, L., Rojas, A., Delgado, R., Knowles, R., and Moncada, S. 1993. Chlorpromazine inhibits both the constitutive nitric oxide synthase and the induction of nitric oxide synthase after LPS challenge. Biochem. Biophys. Res. Commun., 196: 280-286.

Satterwhite, L.L. and Pollard, T.D. 1992. Cytokinesis. Curr. Opin. Cell Biol., 4: 43-52.

Schroeder, T.E. 1968. Cytokinesis: filaments in the cleavage furrow. Exp. Cell Res., 53: 272-276.

Seastone, D.J., Lee, E., Bush, J., Knecht, D., and Cardelli, J. 1998. Overexpression of a novel rho family GTPase, RacC, induces unusual actinbased structures and positively affects phagocytosis in Dictyostelium discoideum. Mol. Biol. Cell., 9: 2891-2904.

Seastone, D.J., Zhang, L., Buczynski, G., Rebetein, P., Weeks, G., Spiegelman, G., and Cardelli, J. 1999. The small Mr Ras-like GTPase Rap1 and the phospholipase C pathway act to regulate phagocytosis in Dictyostelium discoideum. Mol. Biol. Cell., 10: 393-406.

Suzuki, Y., Ohnishi, K., Hirabayashi, T., and Watanabe, Y. 1982. Characterization of an anti-Tetrahymena calmodulin and the immunofluorescent localization in Tetrahymena. Exp. Cell Res., 137: 1-14.

Temesvari, L., Zhang, L., Fodera, B., Janssen, K.P., Schleicher, M., and Cardelli, J.A. 2000. Inactivation of $1 \mathrm{mpA}$, encoding a LIMPII-related endosomal protein, suppresses the internalization and endosomal trafficking defects in profilin-null mutants. Mol. Biol. Cell., 11: 2019-2031.

Watanabe, A., Kurasawa, Y., Watanabe, Y., and Numata, O. 1998. A new Tetrahymena actin-binding protein is localized in the division furrow. $J$. Biochem., 123: 607-613.

Watanabe, A., Yonemura, I., Gonda, K., and Numata, O. 2000. Cloning and sequencing of the gene for a Tetrahymena fimbrin-like protein. $J$. Biochem., 127: 85-94.

Watanabe, S., Hirose, M., Miyazaki, A., Tomono, M., Takeuchi, M., Kitamura, T., and Namihisa T. 1988. Calmodulin antagonists inhibit the phagocytic activity of cultured Kupffer cells. Lab. Invest., 59: 214-218.

Watanabe, Y., Numata, O., Kurasawa, Y., and Katoh, M. 1994. Cultivation of Tetrahymena cells. In Cell Biol. (Celis, J.E., ed.). Academic Press, California. 1: 398-404.

Williams, N.E. and Luft, J.H. 1968. Use of a nitrogen mustard derivative in fixation for electron microscopy and observations on the ultrastructure of Tetrahymena. J. Ultrastruct. Res., 25: 271-292.

Williams, N.E. and Bakowska, J. 1982. Scanning electron microscopy of cytoskeletal elements in the oral apparatus of Tetrahymena. J. Protozool., 29: 382-389.

(Received for publication, August 28, 2000

and in accepted, September 14, 2000) 